\title{
Novas faces da história da medicina na América Latina
}

\author{
New facets of the history of medicine in \\ Latin America
}

\author{
Claudio Bertolli Filho \\ Professor da Universidade Estadual Paulista \\ Departamento de Ciências Humanas da FAAC \\ Av. Eng. Luiz Edmundo Coube, s/n \\ 17033-360 Bauru - SP - Brasil \\ cbertolli@uol.com.br
}

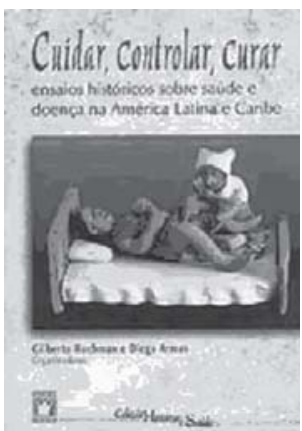

Hochman, Gilberto; Armus, Diego (org.) Cuidar, controlar, curar: ensaios históricos sobre saúde e doença na América Latina. Rio de Janeiro: Ed. Fiocruz, 2004. 568 p. (Coleção História e Saúde.)
$\mathrm{O}$ empenho em indicar o papel do Brasil na América Latina e do chamado 'subcontinente' na perspectiva global flui, de regra, por dois caminhos de certo modo já historicamente consagrados. O primeiro deles ensina que as nações latino-americanas, apesar de suas trajetórias singulares, em conjunto simbolizam uma problemática única alimentada pelo entrelaçamento do tradicionalismo cultural e das condições próprias do subdesenvolvimento. Em razão de fatores culturais e/ou da posição periférica da região, pontifica-se até mesmo que, no campo da medicina, a modernização e a melhor eficiência dos serviços médico-sanitários instalados ao sul do Rio Grande só podem ocorrer mediante a adoção dos modelos formulados nos países centrais, especialmente os Estados Unidos. Tal tradição, ainda hoje enraizada no pensamento das elites latino-americanas, ganhou maior aceitação a partir da Segunda Guerra Mundial, quando vários estudos fomentados em nome do 'panamericanismo' comandado pelos norte-americanos aplicaram-se em denunciar as precárias condições da saúde e da medicina da América Latina e a necessidade de corrigi-las segundo as propostas da modernidade yankee.

A outra postura, baseada em um punhado de argumentos - que abrangem desde a extensão territorial 'macro' ou 'micro', as diferenças favorecidas pela colonização espanhola e portuguesa e a dinâmica própria da cultura e da sociedade de cada uma das nações latino-americanas -, explica que cada país constitui-se em uma realidade própria, pouco havendo em comum que possibilite um diálogo e a troca de experiências mais amplas. Esta suposição ganha cores mais fortes no contexto brasileiro, que, além de buscar se apresentar como culturalmente pouco permeável às nações vizinhas, postula a condição de terri-tório diferenciado no plano sócio-econômico. Assim, a condição de 'país em desenvolvimento' e, mais recentemente, de 'emergente' cria a sensação de que o Brasil estaria mais alinhado aos Estados mais ricos do mundo do que às demais nações latino-americanas, abrindo rotas alter-nativas à Argentina e ao México. Nesse sentido, reitera-se uma vez mais a adoção dos esquemas médico-sanitários vigentes nos países centrais, mesmo que com sensíveis adaptações.

Cuidar, controlar, curar: ensaios históricos sobre saúde e doença na América Latina e Caribe é uma obra coletiva organizada pelo brasileiro Gilberto Hochman e pelo argentino Diego Armus. O livro assume a tarefa ímpar 
de trilhar um terceiro caminho para o entendimento da América Latina através da adoção de um enfoque histórico-antropológico que coloca em destaque uma variedade de questões relativas à saúde coletiva regional. Em suas páginas, assume-se implicitamente que, vivenciando uma mesma condição periférica, mesmo assim cada país apresenta peculiaridades significativas em relação à percepção e ao tratamento das doenças, à organização das instituições de saúde, ao controle sanitário da população e à recepção e instrumentalização das propostas médicas importadas. Se cada nação comporta uma experiência médico-sanitária própria, não se perde de vista que há também muito em comum, assim como as mediações entre o nacional e o internacional contam tanto com a adoção e adaptação de modelos importados quanto com a busca de soluções originais para os problemas sanitários locais.

Fala-se, portanto, de uma leitura em boa dose inovadora da América Latina através do enfoque de um conjunto de temas que, sob grandes lentes, podem ser definidos como pertinentes à história da medicina. Para sua concretização, os coordenadores da iniciativa convocaram pesquisadores atuantes no Brasil e em vários outros centros do continente - também nos Estados Unidos - para produzirem um amplo painel do passado e do presente da saúde latino-americana. Em resultado, o leitor é presenteado com uma rica coleção de análises que enfoca não só a experiência brasileira, mas também oito outras realidades continentais, tendo como cenário Argentina, Bolívia, Colômbia, Costa Rica, Haiti, México, Peru e Porto Rico.

Privilegiando o século XX, o livro anuncia a polifonia de certa forma harmoniosa registrada na trajetória da medicina latino-americana, buscando enfatizar o estado de tensão imperante nas relações entre os agrupamentos populares e os agentes médico-burocráticos dos Estados nacionais e entre estes e as propostas, se não imposições, esboçadas no exterior. Nesse processo, configura-se o empenho dos autores em se irmanarem em um esforço registrado por Hochman e Armus como 'coletivo, multidisciplinar e multicêntrico'.

A importância da coletânea encontra-se no fato de os artigos que a compõem enfatizarem facetas cruciais da saúde e da doença latinoamericana em um ambiente orquestrado por um complexo processo modernizador, até mesmo no que se refere ao setor científico. No campo médico-sanitário tal circunstância não implicou a transferência automática e acrítica dos modelos importados, o que não exclui de questionamento os dispositivos arquitetados pelas elites para, em nome da saúde, estabelecer novas formas de controle da população e dos agentes de saúde. Nesse encaminhamento, apesar dos cruzamentos de perspectivas existentes em um mesmo escrito, o que abre possibilidades para múltiplas combinações, pode-se observar que além de uma rica peça introdutória, na coleção de textos delineiam-se grosso modo três agrupamentos básicos: os artigos tematizados pela institucionalização das práticas médico-científicas, os voltados para a disciplinação das populações e os centrados nas crenças e práticas médicas populares.

O primeiro grupo, pautado sobretudo pela institucionalização das atividades da área da saúde, apresenta um enfoque abrangente e é com- 
posto por cinco textos. O escrito assinado por Ana Maria Carrillo discorre sobre as estratégias mobilizadas no México para tornar a medicina acadêmica o único saber legalmente admitido para o tratamento da saúde popular, reforçando com isso o poder interventor de seus praticantes e, paralelamente, garantindo um status social diferenciado aos graduados pelas escolas médicas oficiais não só em relação aos curadores do povo, mas também junto às demais profissões assumidas pela elite. A experiência brasileira é enfatizada por Jaime Larry Benchimol através da análise do processo de busca de legitimação dos modelos preconizados pela medicina pasteuriana; o desafio representado pela febre amarela foi mobilizado para a institucionalização da microbiologia como saber e prática eficiente na luta contra o mal amarílico e na proteção geral da saúde coletiva.

Na seqüência, ainda contextualizados no cenário nacional, Nísia Trindade e Gilberto Hochman abordam a constituição do credo sanitarista, o qual se impôs não só como instrumento de formas de intervenção no tecido social que se aproximavam da truculência coronelística como também como arsenal para a construção de novas e estigmatizadoras versões das classes subalternas. Esse eixo também foi explorado, com abrangência geográfica maior, por Sérgio Carrara. Nesse conjunto destaca-se ainda uma instigante abordagem feita por Nancy Leys Stepan sobre o pensamento eugenista moldado segundo as necessidades da elite brasileira, demonstrando que, diferentemente do que tem sido proposto por numerosos estudiosos, a eugenia ganhou uma identidade própria e vigorosa no país. Não sendo apenas uma mera cópia do que estava sendo traçado no exterior, a eugenia atingiu dimensões maiores ao ser parcialmente incorporada pelas ações patrocinadas ou chanceladas pelo Estado. Em síntese, o esforço pela institucionalização de novos saberes científicos favoreceu uma nova 'engenharia simbólica' cujo resultado foi a articulação de novos pólos geradores de identidades, tanto da nacionalidade como um todo quanto dos profissionais da saúde que se apresentavam afinados com os ditames da 'nova medicina'.

O enfoque centrado nas estratégias intervencionistas da medicina no campo coletivo é explorado privilegiadamente em cinco outros textos. O empenho médico no combate aos chamados 'males sociais', dentre os quais se destacavam a tuberculose, a sífilis e o alcoolismo, mostrou-se como artifício dominante para a normatização e disciplinação grupal sob a rubrica da 'higiene social' e, ao mesmo tempo, como fator de confirmação das identidades danosas atribuídas às camadas sociais mais pobres. Analisando a Colômbia, Carlos Ernesto Noguera mostra que a ação antialcoólica, inaugurada em 1886, visava ao combate ao consumo da chicha, fermentado típico de vastos contingentes indígenas. $\mathrm{O}$ autor chama atenção para o fato de que as autoridades sanitárias e os moralistas pouco fizeram para inibir o consumo de outras bebidas, tais como a cerveja e o uísque, que eram fartamente consumidas por outros grupos da população. Tudo leva a crer que a campanha fazia parte, sobretudo, da desqualificação da própria cultura indígena e de seus hábitos ancestrais. Focalizando a Bolívia, Ann Zulawski aponta que lá também os agrupamentos autóctones e os miscigenados foram alvo de percepções estigmatizadoras; o estudo das atividades de um manicômio naquele país põe às claras que os indígenas eram pacientes preferenciais da instituição, 
enquanto seus médicos pontificavam que o 'declínio mental' devia-se à 'decadência racial' dos índios e dos grupos miscigenados, os quais precisavam ser internados e 'corrigidos' ou simplesmente isolados da comunidade dos 'sadios'. Da mesma forma, no Brasil o empenho para o saneamento urbano, sob a lógica positivista adotada pelas oligarquias, desvela-se no estudo elaborado por Luiz Antonio de Castro Santos como o caminho adotado para a doutrinação e manipulação das populações urbanas; a modernização conservadora ganhava aliados na medicina e na educação, contando para isso com o incentivo e o apoio financeiro e técnico de instituições estrangeiras.

Incluídos nesse grupo, outros estudos indicam que as populações latino-americanas não se mostravam passivas frente às medidas intervencionistas - ou à falta delas - preconizadas pelo Estado e pelo seu braço sanitário. Diante das incertezas da própria medicina oficial, o povo rebelava-se, buscando garantir os apoios que julgava melhores para si. Na Argentina, como analisado por Diego Armus, em nome da prevenção da tuberculose a população confrontou-se com a administração pública, cobrando a adoção de medidas sociais e médicas que minimizassem a ameaça sanitária. Mais do que isto, por duas décadas os argentinos exigiram que as autoridades colocassem à disposição a vacina Pueyo, considerada eficiente tanto para a proteção quanto para a cura da tísica, contrariando com isso o posicionamento da maior parte dos clínicos; a recusa oficial levou o povo a recorrer insistentemente à imprensa para exigir que as autoridades sanitárias governamentais disponibilizassem a droga para quem a requeresse. As relações sempre tensas entre a esfera médica e os anseios populares reiteravam a necessidade de uma disciplinação mais consistente das massas, tarefa a cargo da ação pedagógica. Tomando como exemplo a Costa Rica, Steven Palmer analisa a intensa participação da Fundação Rockefeller em prol da educação em saúde, atividade que a instituição norte-americana desenvolveu em praticamente toda a América Latina. É importante destacar que sempre houve atritos entre os especialistas provenientes dos Estados Unidos e os médicos latino-americanos, sendo necessárias adaptações das propostas imperialistas para os contextos nacionais. Ficava evidente que, para efetivar o compromisso educador, a primeira tarefa das equipes patrocinadas por Rockefeller era doutrinar as elites médicas nacionais, e, se isso não fosse possível, administrar negociações favoráveis aos interesses da Fundação.

$\mathrm{O}$ último conjunto de textos reúne quatro estudos e guarda como centro de indagações a cultura médica popular. Os medos suscitados por um mundo fantasmagórico e propiciador ou inibidor das doenças estão presentes em todas as culturas, sobretudo nas tradicionais, levando à combinação de várias estratégias não aprovadas pela medicina oficial para a proteção ou recuperação da saúde, como ensina uma análise motivada pelas práticas populares no sul brasileiro e assinada por Beatriz Teixeira Weber. Em Porto Rico, Benigno Trigo indica que as explicações e atitudes populares na área da saúde foram invocadas pelos grupos no poder para pretensamente atestarem a condição bárbara e insubordinada dos trabalhadores rurais, justificando-se a disseminação das doenças e a baixa produtividade no trabalho como conseqüência dos va- 
lores e crenças de grupos recalcitrantes à lógica da vida moderna e aos cuidados 'racionais' com a saúde. As doenças emergentes, como a Aids, apesar de seu caráter de 'enfermidade moderna', segundo Paul Farmer, também contam com explicações populares que assumem a infecção como produto da feitiçaria. Tais versões vêm sendo trabalhadas pelas equipes médicas atuantes no Haiti.

Nesse conjunto inclui-se ainda um estudo de Marcos Cueto, que ganha destaque ao focar as práticas higiênicas e curativas em uma comunidade rural do Peru. Nele demonstra-se que mais do que a ausência de lógicas, as práticas tradicionais indígenas guardam uma positividade que pode ser, ao menos em parte, aproveitada na atuação da medicina acadêmica durante as ações promovidas junto aos agrupamentos tradicionais.

Em suma, o livro capitaneado por Hochman e Armus apresenta fragmentos fundamentais do mosaico composto pelas experiências com a saúde e com a doença na América Latina. No conjunto, a obra aponta para uma nova história da medicina que, longe do caráter colonizador e ufanista, anuncia as condicionantes do encontro entre distintas temporalidades que colocam em confronto o tradicional e o moderno, as práticas preventivas e curativas populares e o saber acadêmico, a sociedade e o Estado, o nacional e o internacional. Além disso, a obra também faz o leitor perceber a importância vital dos estudos que colocam em contato as diferentes faces da experiência médico-sanitária latino-americana, esclarecendo as diferenças e as identidades entre as experiências nos países estudados.

O significado ímpar da obra convida à reflexão e também permite a esperança de que a iniciativa de um diálogo continental em nome da saúde, da doença e de sua história não se esgote apenas no volume resenhado. Espera-se, isto sim, que este seja apenas o primeiro fruto de uma série de obras que tenham como objetivo oferecer uma visão abrangente, comparativa e integrada da história da medicina na América Latina.

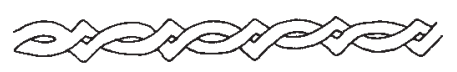

